\title{
Analysis of Fiber Drawing in Wet Spinning for Surface Roughness
}

\author{
Yuta FUKUI*, Tatsuya TERAMUA, and Tomoyuki YoshIMI \\ Engineering Research Laboratories, KANEKA CORPORATION, 1-8, Miyamaecho, Takasagocho, Takasago, Hyogo, 676-8688, \\ Japan
}

\begin{abstract}
The drawing process behavior was investigated with focus on fiber stretching speed (spinning acceleration) to improve luster quality of fibers. Wet spinning method has a limitation of low luster at high spinning speed. It was determined that (1) luster quality could be evaluated by arithmetic average $(R \Delta a)$ of fibers, which indicated the roughness, and (2) the roughness of the fiber was related to the spinning acceleration through the analysis of $R \Delta a$. Spinning acceleration was measured by chasing markers that were used to tie fibers. Regardless of the length of spinning bath, fibers were mainly stretched during the first stretching stage. Therefore, a multistep drawing method was used. In the case where the drawing ratio was $220 \%$ by one-step, $R \Delta a$ was $10.1^{\circ}$; however by multi-step drawing $\left(1^{\text {st }}\right.$ and $2^{\text {nd }}$ drawing ratios were $\left.148.3 \%\right), R \Delta a$ decreased to $8.3^{\circ}$. The multi-step drawing method enabled the reduction in fiber roughness by preventing a sudden change in fiber stress. In addition, high temperatures improved the fiber roughness. At high temperatures, roughness decreased despite the high acceleration because the fiber was easier to stretch than at low temperatures.
\end{abstract}

\section{Introduction}

Wet spinning method has shown high productivities for a long time. This method with acrylic polymer is preferred to construct fibers such as human hair products because of good texture and feel. However, it is limited by low luster at high spinning speeds.

Typically, wet spinning method involves two drawing processes for determining fiber strength. First drawing process is in the bath and the second drawing process is after drying, and the drawing ratio is approximately 200 $800 \%$ (Ohe et al., 1967). In this report, drawing ratio means ratio of rolls speed between inlet and outlet. For example, When inlet rolls speed is $10 \mathrm{~cm} / \mathrm{s}$ and outlet rolls speed is $20 \mathrm{~cm} / \mathrm{s}$, the drawing ratio is $200 \%$.

When sample is taken at high draw ratio or high speed spinning, drawing fibers sometimes have many wrinkles on the surface. It has been reported that wrinkles on the coagulated fiber side surface increase in the stretching stage by drawing below secondary transition temperature (Sawanishi et al., 1998). The fiber roughness studies have focused on "dried fiber" in the drawing process. Drawing behavior in the bath was reported only for desolvation (Takeda et al., 1964). Desolvation in the bath is related to the fiber stretching ratio, but the relationship between roughness and drawing behavior has not yet been clarified.

In this study, we focused on roughness in drawing process in the bath and we investigated fiber behavior during drawing. By controlling the factors that result in fiber roughness in the bath can allow high productivity by wet spinning.

\section{Experimental}

\subsection{Materials}

Polymer solution was prepared by mixing modacrylic copolymer (acrylonitrile : vinyl chloride $=50: 50(\mathrm{abt}$.) powder, Dimethyl sulfoxide (DMSO), and pure water. Modacrylic copolymer was synthesized by emulsion polymerization.

\subsection{Evaluation of stretching characteristics}

Figure 1 illustrates the schematic experimental apparatus in one-step drawing. Polymer solution was supplied by the gear pump from $3 \mathrm{~L}$ tank to the coagulation bath $\left(1^{\text {st }}\right.$ bath). Polymer solution was coagulated and fibers were formed in the $1^{\text {st }}$ bath. Extruded fibers from 10-hole nozzle were rolled up and introduced to the drawing bath ( $2^{\text {nd }}$ bath) connected to the $1^{\text {st }}$ bath. After drawing process, fiber structure is getting dense and that fiber strength is increased.

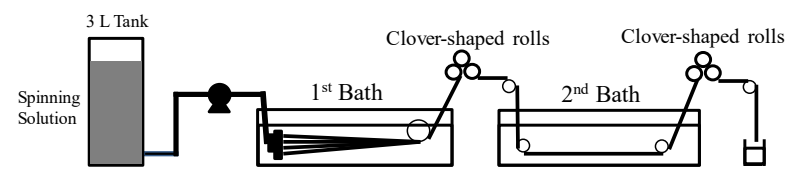

Figure 1. Experimental apparatus of spinning process

\footnotetext{
* Corresponding author: Yuta.Fukui@kaneka.co.jp
} 
Fibers samples were collected by installing clover-shaped rolls after each bath. In one-step drawing, the drawing ratio was $150-290 \%$, and in two-step drawing, two baths were assembled. Figure 2 illustrates the schematic experimental apparatus of two-step drawing. A bath of 2.0-5.0 $\mathrm{m}$ was used for drawing and DMSO concentration was $50 \mathrm{wt} . \%$ in each bath.

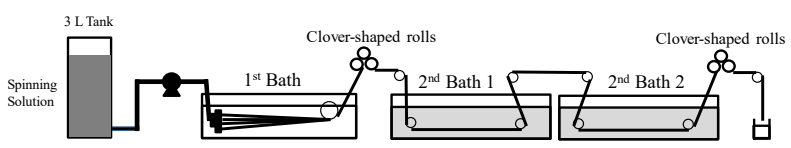

Figure 2. Experimental apparatus of drawing process.

For the evaluation of stretching behavior, the moving speed was measured by a digital camera. The stretching phenomena was expressed by equation (1). Acceleration $\alpha$ is typically affected by stretching ratio, temperature, and fiber tension. In this case, it was assumed that $\alpha$ was constant in any stretching ratio under constant temperature and fiber tension.

$$
L=v_{0} t+\frac{1}{2} \alpha t^{2}
$$

\subsection{Fiber characterization}

To investigate the factors that cause low luster at high spinning speed, scanning electron microscopy (SEM; HITACHI; S-4800) was utilized to observe the fiber side surface. Additionally, the fiber arithmetic average $(R \Delta a)$, which indicated fiber roughness, was evaluated using a laser microscope (KEYENCE; VK-X100).

The drawability is affected by the drawing bath temperature. Therefore, thermal mechanical analysis (TMA; SII Seiko Instruments Inc.; TMA 150) was utilized to evaluate the relationship between temperature and the drawing response for a single fiber. DMSO concentration in the drawing bath was $50 \mathrm{wt} . \%$ and the load was $14 \mathrm{mN}$.

\section{Results and Discussion}

\subsection{Fiber roughness}

Figure 3 shows the fiber side surface of fiber products of high and low luster level using laser microscope. To satisfy high luster level, it is necessary that $R \Delta a$ is lower than $12^{\circ}$ by evaluating standard fiber products.
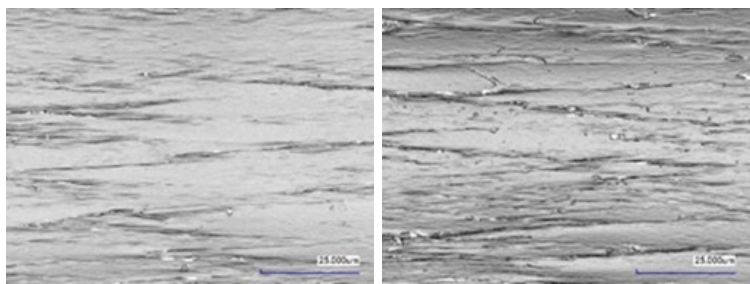

Figure 3. Fiber side surface of high (left) and low (right) luster level of in fiber products.

\subsection{Multi-step drawing}

Thereafter, $R \Delta a$ was measured in the drawing fiber side surface between the high and low productivities. As a result, $R \Delta a$ was $8^{\circ}$ at $8.3 \mathrm{~cm} / \mathrm{s}$ and $21^{\circ}$ at $16.7 \mathrm{~cm} / \mathrm{s}$ (Figure 4). It was speculated that excessive stretching force in a drawing process caused the roughness in fiber side surface; therefore, $R \Delta a$ should be reduced to improve the luster in drawing process.

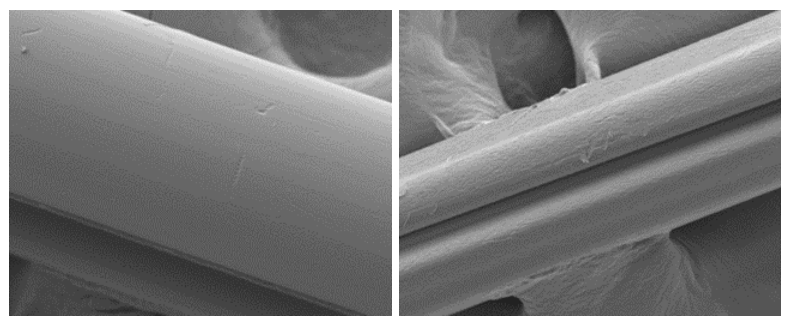

Figure 4. SEM images obtained by stretching the yarn at high speed $(8.3 \mathrm{~cm} / \mathrm{s}$, left $)$ and low speed $(16.7 \mathrm{~cm} / \mathrm{s}$, right).

Next, the stretching behavior was evaluated using parameter $\alpha$. Figure 5 shows a comparison of the experimental stretching behavior in one-step stretching and that of the calculation when $\alpha$ is constant in equation (1). As a result, the stretching behavior could be expressed by equation (1) at constant $\alpha$.

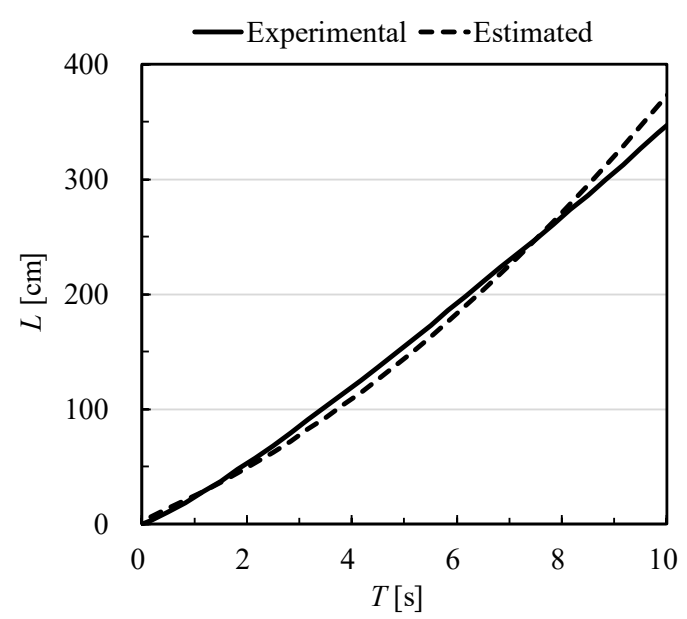

Figure 5. Comparison of experimental and estimated fiber behavior in one-step stretching.

Figure 6 shows one-step drawing and multi-step (two step) drawing behavior. In this experiment, bath temperature was $90^{\circ} \mathrm{C}$ and drawing ratio was $220 \%$. In the case of two-step drawing, drawing ratio in the $2^{\text {nd }}$ bath 1 and $2^{\text {nd }}$ bath 2 were $148.3 \%$. In one-step stretching, the fibers were suddenly stretched in the first half of the bath, but two-step drawing showed slower stretching due to the control of drawing ratio in each bath.

In addition, the time required to achieve the target velocity $(24.8 \mathrm{~m} / \mathrm{min})$ was measured. In one-step drawing, the required time was approximately $9 \mathrm{~s}$ and in two-step stretching, it was approximately $12 \mathrm{~s}$. The values for $\alpha$ were calculated in both cases. It was determined that $\alpha$ was $3.5 \mathrm{~cm} / \mathrm{s}^{2}$ in one-step drawing and $0.93 \mathrm{~cm} / \mathrm{s}^{2}$ (first step) and $2.4 \mathrm{~cm} / \mathrm{s}^{2}$ (second step) in two-step drawing. 
Furthermore, $R \Delta a$ decreased from $10.1^{\circ}$ to $8.1^{\circ}$ upon changing from one-step drawing to two-step drawing. Therefore, two-step drawing was effective in decreasing $\alpha$ and $R \Delta a$ (Table 1 ) because $\alpha$ was decreased upon changing to two-step drawing.

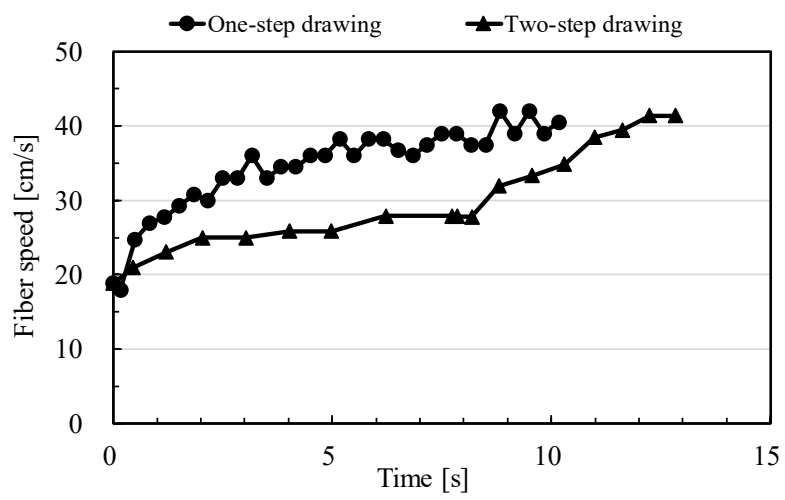

Figure 6. Comparison of stretching behavior in one-step and two-step drawing at $90^{\circ} \mathrm{C}$.

Table 1. Comparison of one-step and two-step drawing

\begin{tabular}{|c|c|c|c|}
\hline & $\begin{array}{l}\text { The time required to } \\
\text { achieve the target } \\
\text { velocity [s] }\end{array}$ & $\begin{array}{c}\alpha \\
{\left[\mathrm{cm} / \mathrm{s}^{2}\right]}\end{array}$ & $\begin{array}{l}R \Delta a \\
I^{\circ} \quad 1\end{array}$ \\
\hline One-step drawing & 12 & 3.5 & 10.1 \\
\hline Two-step drawing & 9 & 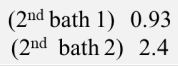 & 8.1 \\
\hline
\end{tabular}

\subsection{Relationship $R \Delta a$ and $\alpha$}

Figure 7 shows the relationship between $R \Delta a$ and $\alpha$ in one-step drawing at $50^{\circ} \mathrm{C}$. When $\alpha$ was increased, $R \Delta a$ also increased. It was necessary to decrease the roughness of fiber side surface to satisfy $R \Delta a$ value below $12^{\circ}$ in the drawing fiber. It was determined that for $R \Delta a$ below $12^{\circ}$, $\alpha$ must be below $2.5 \mathrm{~cm} / \mathrm{s}^{2}$.

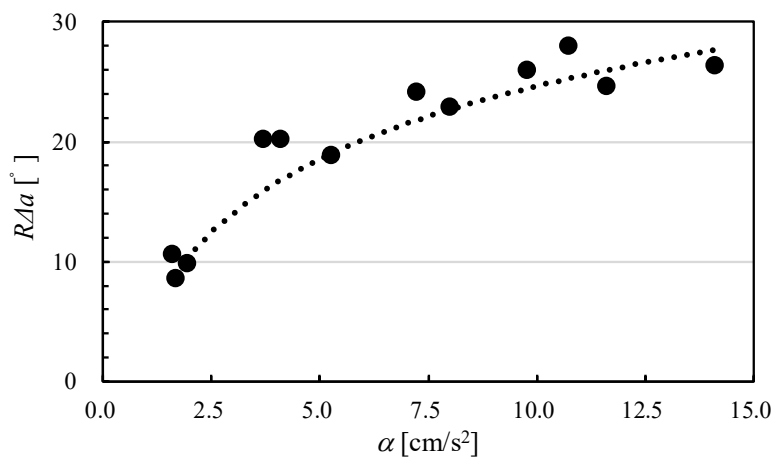

Figure 7. Relationship between $R \Delta a$ and $a$ in one-step drawing at $50^{\circ} \mathrm{C}$

\subsection{Temperature dependency of the upper limit}

of $\alpha$

We examined the temperature dependency of the upper limit of $\alpha$, which satisfied the $R \Delta a$ value of below $12^{\circ}$. Figure 8 illustrates the relationship between $\alpha$ and temperature, with $R \Delta a$ as a parameter in one-step stretching. The value of $R \Delta a$ was measures from $40-80^{\circ} \mathrm{C}$ at every $10^{\circ} \mathrm{C}$ interval. The dashed line represents the upper limit of $\alpha$, which satisfied $R \Delta a$ value of below $12^{\circ}$. It was determined that the allowable range of acceleration $\left(R \Delta a\right.$ below $\left.12^{\circ}\right)$ significantly increased when the temperature exceeded $60^{\circ} \mathrm{C}$. Therefore, it is important that fiber temperature is $>60^{\circ} \mathrm{C}$ in the drawing process for a decrease in roughness.

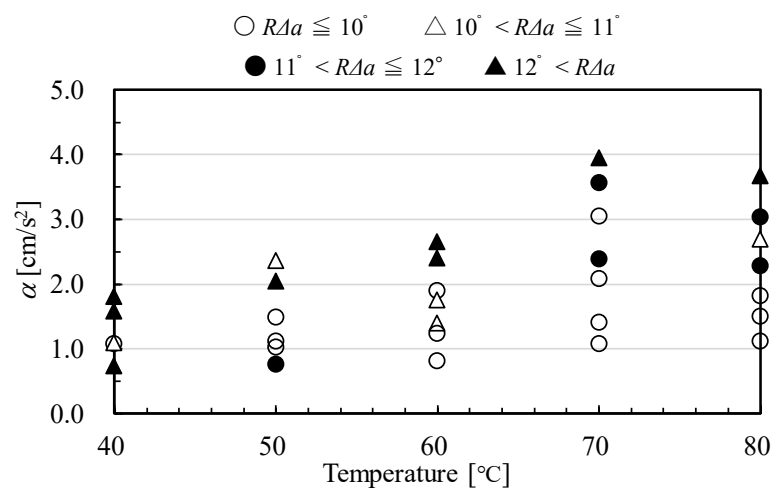

Figure 8. Upper limit of $\alpha$, which satisfied the $R \Delta a$ value of below $12^{\circ}$ ).

To understand this phenomenon, strain was measured using TMA. Figure 9 shows the TMA result. Fiber strain gradually increased when fiber temperature is above $55^{\circ} \mathrm{C}$ It was assumed that increase in upper limit of $\alpha$ at $60^{\circ} \mathrm{C}$ was due to the fiber material characteristics. Therefore, an increase in the temperature during drawing process corresponds to a decrease in the fiber stress.

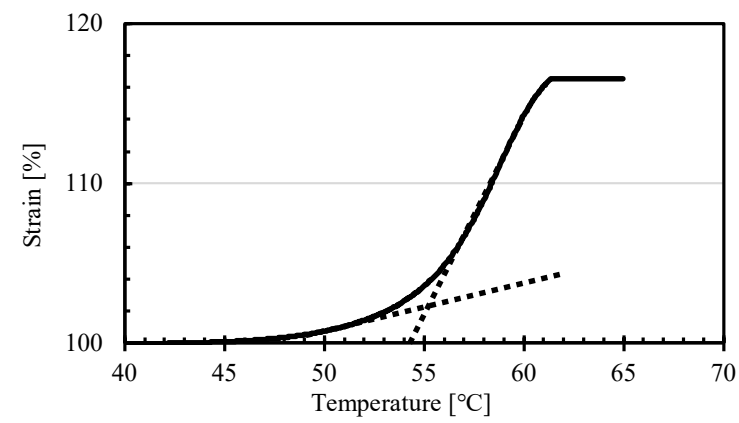

Figure 9. Stretch response to temperature.

\subsection{Optimal ratio of each bath in two-step}

\section{drawing}

We investigated optimal ratio of each bath in two-step drawing. In this experiment, we changed $2^{\text {nd }}$ bath 1 drawing ratio from $120 \%$ to $180 \%$ and at that time we changed $2^{\text {nd }}$ bath- 1 temperature each condition.

Table 2. Experimental conditions for optimizing drawing ratio.

\begin{tabular}{|c|c|c|c|c|}
\hline $\begin{array}{c}\text { Total } \\
\text { Drawing } \\
\text { ratio [\%] }\end{array}$ & $\begin{array}{c}\mathbf{2}^{\text {nd }} \text { bath 1 } \\
\text { drawing } \\
\text { ratio [\%] }\end{array}$ & $\begin{array}{c}\mathbf{2}^{\text {nd }} \text { bath 2 } \\
\text { drawing } \\
\text { ratio [\%] }\end{array}$ & $\begin{array}{c}\mathbf{2}^{\text {nd }} \text { bath 1 } \\
\text { temperature }\left[{ }^{\circ} \mathbf{C}\right]\end{array}$ & $\begin{array}{c}\mathbf{2}^{\text {nd }} \text { bath 2 } \\
\text { temperature }\left[{ }^{\circ} \mathbf{C}\right]\end{array}$ \\
\hline \multirow{5}{*}{220} & 120 & 183 & & \\
& 135 & 163 & & \\
& 150 & 147 & $50 / 60 / 70$ & 90 \\
& 165 & 133 & & \\
& 180 & 122 & & \\
& & & & \\
\hline
\end{tabular}


Figure 10 illustrates the relationship $R \Delta a$ and $2^{\text {nd }}$ bath 1 ratio in each temperature. As a result, we found that when $T_{1}$ was lower, for example $T_{1}=50^{\circ} \mathrm{C}, 2^{\text {nd }}$ bath 1 ratio was better to decrease $R \Delta a$. Otherwise when $T_{1}$ was over $60^{\circ} \mathrm{C}$, $2^{\text {nd }}$ bath 1 ratio was not effective until around half ratio of total.

These results mean two-step drawing have adjustable function in proportion to $2^{\text {nd }}$ bath 1 temperature to decrease $R \Delta a$ by prevent fiber stress.

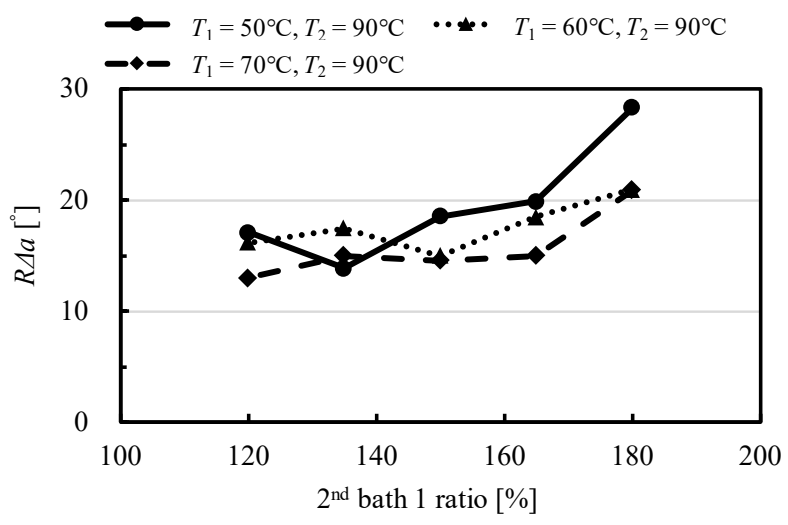

Figure 10. Stretch response to temperature.

\section{Conclusion}

To improve the fiber luster quality in wet spinning, we focused on the drawing process in the bath. It was determined that to decrease the roughness of fiber side surface, acceleration in drawing process should be decreased. In high speed spinning, selecting two-step drawing was an effective method to decrease the acceleration at stretching stage. Slow stretching prevented extra stress in the fiber such that the roughness of the fiber surface decreased and the fiber luster level increased.

In addition, the temperature of the bath is also related to with fiber roughness. Secondary transition temperature in modacrylic polymer is approximately $60^{\circ} \mathrm{C}$ and the upper limit of $\alpha$ is above $60^{\circ} \mathrm{C}$. At temperatures above $60^{\circ} \mathrm{C}$, roughness decreased despite the high acceleration because the fiber was easier to stretch than at low temperatures.

Nomenclature

$\begin{array}{lll}\alpha & =\text { Drawing acceleration }\left[\mathrm{cm} / \mathrm{s}^{2}\right] \\ L & =\text { Drawing bath length }[\mathrm{cm}] \\ v_{0} & =\text { First spinning speed }[\mathrm{cm} / \mathrm{s}] \\ t & =\text { Drawing time }[\mathrm{s}] \\ R \Delta a & =\text { Fiber's arithmetic average }\left[{ }^{\circ}\right] \\ T_{1} & =2^{\text {nd }} \text { bath } 1 \text { temperature }\left[{ }^{\circ} \mathrm{C}\right] \\ T_{2} & =2^{\text {nd }} \text { bath } 2 \text { temperature }\left[{ }^{\circ} \mathrm{C}\right]\end{array}$

\section{Acknowledgements}

We would like to thank Editage (www.editage.com) for English language editing.

\section{References}

Ohe, H., M. Ishikawa, S. Isaka, B. Hada, S. Miwa, K. Fukumi, and T. Morita; "Studies on the Production of Acrylic Fiber by Wet Spinning. 5. Spinnability of Acrylic Fiber, Mainly on the Tensile Properties of Extruded Giber in each Spinning Process," J. Soc. Fiber Sci. Technol., 23, 410-417 (1967)

Sawanishi, S., Y. Shiomi, and A. Yamane; "Manufacturing Method of Acrylic Fiber with Surface Smoothness," Japan Patent Disclosure 1988-61409 (1998)

Takeda, H. and A. Kato; "Studies on Acrylic FiberSolvent Removal Phenomena of Coagulated Filament in an Elevated Temperature Bath (Drawing in Solvated State)," J. Chem. Soc. Jpn., 67(8), 1285-1289 (1964) 